\title{
GAYA KEPEMIMPINAN KEPALA SEKOLAH DALAM MENGELOLA SMP NEGERI 2 RAMBATAN
}

\author{
Nofii Ade Siska \\ Guru PAI di SMP Negeri 2 Rambatan \\ Pincuran Gadang Nagari Simawang, Kec. Rambatan, Tanah Datar \\ Email: dhe_ya89@yahoo.com
}

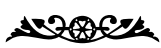

\begin{abstract}
This research was purposed at describing the leadership style of headmaster in Secondary School 2 Rambatan. This research used qualitative paradigm by applying case study method. In collecting the data the researcher used tape recorder, interview guideline and observation sheet and applied the techniques of interview, observation and documentary study. The informants of this research were 28 persons which consist of headmaster, the teacher and the administration staff of Secondary School 2 Rambatan. The results of the research obtained that (1) in managing teachers' competence the headmaster applied strict style and strongly discipline; (2) In motivating teachers' to improve the students' achievement the headmaster applied democratic style; (3) In developing curriculum the headmaster applied democratic style; and (4) in managing financial resources the headmaster applied strict style, democratic, and participative.
\end{abstract}

Keywords: Leadership Style, Headmaster, Secondary School, Rambatan

\section{PENDAHULUAN}

SMP Negeri 2 Rambatan merupakan sebuah sekolah yang terletak di Kenagarian Simawang, Kecamatan Rambatan, Kabupaten Tanah Datar, Provinsi Sumatra Barat. Sekolah ini berdiri sudah 20 tahun, dan sudah 8 kali pergantian kepala sekolah sejak berdirinya. Dari delapan Kepala Sekolah itu ada salah seorang Kepala Sekolah yang sangat menonjol dan bisa membuat sekolah lebih baik dari kepemimpinan kepala sekolah sebelumnya, yakni Kepala Sekolah yang sekarang. Beliau dipindahkan pada tahun 2010 dari SMP Negeri 3
Batipuh Kecamatan Batipuh Kabupaten Tanah Datar.

Setelah 3 tahun Kepala Sekolah tersebut memimpin SMP Negeri 2 Rambatan sudah banyak prestasi sekolah yang beliau dapatkan antara lain (hasil observasi peneliti) a) tahun 2011 sekolah berada pada peringkat 17 dari 53 SMP yang ada di kabupaten tanah datar; b) tahun 2012 sekolah berada pada peringkat 11 dari 53 SMP yang ada di kabupaten tanah datar; c) pada tahun 2012 juara 1 lomba sekolah sehat (LSS) tingkat kabupaten Tanah Datar (SK Bupati Tanah Datar); d) pada tahun 2012 juara 1 lomba 
Sekolah Adiwiyata tingkat kabupaten Tanah Datar (SK Bupati Tanah Datar); e) pada tahun 2013 juara 2 lomba sekolah sehat tingkat provinsi (SK Gubernur Sumatra Barat); f) pada tahun 2013 kategori pertama Sekolah Adiwiyata tingkat nasional, sekarang membina 13 sekolah baik SMP maupun SD yang ada di Kabupaten Tanah Datar untuk menjadi Sekolah Adiwiyata, hal ini sebagai langkah untuk maju Sekolah Adiwiyata tigkat ASEAN (SK Gubernur Sumatra Barat dan dari Kementrian Lingkungan Hidup); g) sebelum kepala sekolah sekarang bertugas, akreditasi sekolah C, dan pada tahun 2013 kepala sekolah sekarang mengajukan penilaian akreditasi, dan akreditasi pun berubah menjadi B+; h) pada tahun 2012, kepala sekolah sekarang juara satu kepala sekolah berprestasi tingkat Kabupaten Tanah Datar; dan i) pada tahun 2013 kepala sekolah sekarang juara tiga Kepala Sekolah berprestasi tingkat provinsi.

Padahal ketika melihat kondisi sebelum beliau bertugas di SMP Negeri 2 Rambatan, SMP tersebut sangat memperhatinkan, dan sulit untuk mendapatkan prestasi di atas. Di mana gedung sekolah tidak tertata dengan baik, kedisiplinan guru masih kurang, mutu akademik siswa jauh di bawah standar bahkan peringkat SMP Negeri 2 Rambatan sebelum bapak Kepala Sekolah yang sekarang datang peringkatnya paling rendah di antara SMP Negeri yang ada di Kabupaten Tanah Datar. Fenomena ini peneliti dapat dari observasi sejak peneliti menjadi guru honorer di SMP Negeri 2 Rambatan dari tahun 2011 sampai 2013. Fenomena ini juga peneliti peroleh melalui beberapa orang guru senior yang telah lama bertugas di SMP Negeri 2 Rambatan melalui wawancara.

Dari beberapa hasil wawancara dan dokumentasi yang peneliti dapatkan, Kepala Sekolah mulai bertugas tahun 2010, maka peneliti membuat perbandingan keadaan sekolah sebelum 2010 dan keadaan sekolah setelah 2010 sebagai berikut.

Tabel Perbandingan Kondisi Sekolah Sebelum 2010 dan Kondisi Sekolah Setelah 2010

\begin{tabular}{|c|l|l|}
\hline NO & SEBELUM 2010 & SETELAH 2010 s/d 2013 \\
\hline 1 & Akreditasi sekolah C & Akreditasi sekolah B+ \\
\hline 2 & $\begin{array}{l}\text { Belum ada ruang guru yang } \\
\text { layak }\end{array}$ & Sudah ada ruang guru \\
\hline 3 & Belum ada ruang osis & Sudah ada ruang osis \\
\hline 4 & Belum ada ruang UKS & Sudah ada ruang UKS \\
\hline 5 & Belum ada ruang wakil & Sudah ada ruang kusus wakil \\
\hline 6 & Belum ada ruang BK & Sudah ada ruang BK \\
\hline 7 & Belum ada kantin sekolah & Sudah ada kantin sekolah \\
\hline 8 & Belum ada sumber air bersih & Sudah ada sumber air bersih \\
\hline 9 & $\begin{array}{l}\text { Belum adanya kendaran yang } \\
\text { lansung kehalaman sekolah }\end{array}$ & $\begin{array}{l}\text { Kendaran sudah bisa langsung } \\
\text { ke halaman sekolah }\end{array}$ \\
\hline 10 & Wc guru 1 buah & Wc guru 5 buah \\
\hline 11 & Wc siswa 2 buah & Wc siswa 23 buah \\
\hline 12 & Belum adanya taman sekolah & Ada taman sekolah \\
\hline 13 & $\begin{array}{l}\text { Belum ada kolaam kusu ikan } \\
\text { disekolah }\end{array}$ & Ada kolam kusus ikan \\
\hline 14 & Belum ada pagar sekolah & Ada pagar sekolah \\
\hline 15 & Belum adanya musalla yang layak & Ada musalla yang layak \\
\hline 16 & Belum ada pustaka yang layak & Ada pustaka yang layak \\
\hline 17 & Belum ada labor bahasa & Ada labor Bahasa \\
\hline 18 & Belum ada bang sampah & Sudah ada bang sampah \\
\hline 19 & $\begin{array}{l}\text { Belum ada lapangan yang layak } \\
\text { untuk berolah raga bagi siswa }\end{array}$ & $\begin{array}{l}\text { Sudah ada lapangan yang layak } \\
\text { untuk berolah raga bagi siswa }\end{array}$ \\
\hline 20 & Belum ada pondok seni siswa & Sudah ada pondok seni siswa \\
\hline 21 & Belum ada pondok mading siswa & Sudah ada pondok madding \\
\hline & & \\
\hline
\end{tabular}

Adapun fokus penelitian ini adalah bagaimana gaya kepemimpinan Kepala SMP Negeri 2 Rambatan dalam mengelola lembaga pendidikan. Dalam penelitian ini, peneliti menguraikan langkah demi langkah untuk mengungkapkan tentang gaya kepemimpinan kepala SMP Negeri 2 Rambatan dalam mengelola lembaga pendidikan. 


\section{METODE PENELITIAN}

Penelitian ini dimaksudkan untuk mengungkapkan tentang gaya kepemimpinan Kepala SMP Negeri 2 Rambatan, Nagari Simawang Kecamatan Rambatam dengan menggunakan pendekatan kualitatif. Pendekatan ini dianggap paling sesuai untuk mengkaji permasalahan dalam penelitian ini, karena inti permasalahannya terkait dengan hal-hal yang aktual saat ini. Menurut Moleong (2005) penelitian kualitatif adalah penelitian yang bermaksud untuk memahami fenomena tentang apa yang dialami oleh subyek peneliti misalnya perilaku, persepsi, motivasi, tindakan dan lain-lain, secara holistik dan dengan cara deskripsi dalam bentuk kata-kata dan bahasa, pada suatu konteks khusus yang alamiah dan dengan memanfaatkan berbagai metode alamiah (Sugiyono, 2008). Ciri-ciri penelitian yang menggunakan pendekatan kualitatif, Moleong (2005) mengkaji dan sintesis dari dua versi yaitu dari Lincaln dan Guba, Bogdan dan Biklen ada 11 antara lain 1) latar ilmiah; 2) manusia sebagai alat (instrumen); 3) metode kualitatif; 4) analisis data secara induktif; 5) teori dari dasar; 6) Deskriptif; 7) lebih mementingkan proses dari hasil; 8) adanya batas yang ditentukan oleh focus; 9) adanya kriteria khusus untuk keabsahan; 11) desain yang bersifat sementara; dan 11) hasil penelitian dirundingkan dan disepakati bersama (Sutopo, 2002).

Adapun yang menjadi tempat penelitian peneliti adalah SMP Negeri 2 Rambatan yang terletak di Nagari Simawang, Kecamatan Rambatan, Kabupaten Tanah Datar. Adapun waktu penelitian ini mulai dari bulan Februari 2015 sampai bulan April 2015. Sumber data dari penelitian ini adalah kepala sekolah dan seluruh guru, karyawan tata usaha dan dokumentasi berupa foto-foto sekolah sebelum 2010 dan foto-foto sekolah sesudah 2010 yang ada di SMP Negeri 2 Rambatan. Dalam penelitian ini teknik pengumpulan data yang digunakan adalah wawancara, observasi dan dokumentasi. Wawancara adalah percakapan dengan maksud tertentu yang dilakukan oleh dua pihak, yaitu pewawancara yang mengajukan pertanyaan dan terwawancara yang memberikan jawaban atas pertanyaan itu (Moleong, 2005). Dalam penelitian ini wawancara merupakan metode primer yang peneliti gunakan dalam pengumpulan data. Wawancara digunakan untuk mengetahui dan memperoleh data secara langsung dari obyek penelitian tentang deskripsi kepemimpinan kepala sekolah dalam mengembangkan sokolah baik dari segi sarana dan prasarana maupun dari segi mutu akademik siswa. Kemudian observasi dan dokumentasi digunakan untuk mendapatkan data-data nyata yang mudah diamati secara langsung, seperti letak gedung, sarana dan prasarana, dan proses pelaksanaan pengembangan pendidikan SMP Negeri 2 Ramabatan. Analisis data dalam penelitian kualitatif bersifat induktif dan berkelanjutan. Analisis data yang digunakan adalah analisis data Miles dan Huberman (1992). 


\section{HASIL PENELITIAN DAN PEMBAHASAN}

Berdasarkan hasil wawancara, observasi dan dokumentasi tentang gaya kepemimpinan Kepala Sekolah dalam mengelola SMP Negeri 2 Rambatan adalah sebagai berikut 1) dalam rangka membina dan meningkatkan kompetensi guru, Kepala SMP Negeri 2 Rambatan dalam kepemimpinanya memakai gaya yang tegas keras dan disiplin yang tinggi yang berorentasi pada tugas; 2) dalam rangka membina dan meningkatkan motivasi guru untuk meningkatkan mutu hasil belajar siswa, Kepala SMP Negeri 2 Rambatan memakai gaya demokrasi dalam kepemimpinannya yang berorentasi pada tugas dan manusia; 3 ) dalam rangka mengembangkan kurikulum, Kepala SMP Negeri 2 Rambatan memakai gaya demokrasi dalam kepemimpinanya; 4) dalam rangka mengelola keuangan dan sarana prasarana sekolah, Kepala SMP Negeri 2 Rambatan memakai gaya situasional. Artinya adakalanya kepala sekolah tegas, keras, demokrasi, partisipasi, yang berorentasi pada tujuan.

Kepemimpinan Kepala Sekolah sebagai salah satu fungsi manajemen merupakan faktor yang sangat penting untuk mencapai tujuan organisasi termasuk organisasi sekolah. Kepala Sekolah adalah orang yang diberi tugas dan tanggung jawab mengelola sekolah menghimpun, memanfaatkan, dan menggerakkan seluruh potensi sekolah secara optimal untuk mencapai tujuan. Kepemimpinan kepala sekolah diartikan cara usaha kepala sekolah dalam menggerakkan guru, siswa, staff, orang tua siswa, dan pihak lain yang terkait untuk bekerja, berperan serta guna mencapai tujuan yang telah ditetapkan (Depdiknas, 2001). Berdasarkan pengertian tersebut menunjukkan betapa pentingnya peran kepemimpinan kepala sekolah dalam menggerakkan kehidupan sekolah, memotivasi, membimbing sekolah guna tercapainya tujuan yang diinginkan.

Kepemimpinan merupakan salah satu topik penting dalam mempelajari dan mempraktikkan manajemen. Kepemimpinan berasal dari kata "pimpin" yang berarti tuntun, bina atau bimbing (Usman, 2008). Menurut Sinn (2008) kepemimpinan adalah seni untuk mengatur individu dan masyarakat, serta motivasi semangat mereka untuk meraih tujuan yang telah ditetapkan. Kemudian menurut (Wahjosumido, 2011) kepemimpinan diterjemahkan kedalam istilah sifat-sifat, perilaku pribadi, pengaruh terhadap orang lain, pola-pola interaksi, hubungan kerja sama antar peran, kedudukan dari satu jabatan administratif dan persepsi dari lain-lain tentang legitimasi pengaruh. Bedasarkan pendapat-pendapat tersebut, kepemimpinan merupakan bagian penting manajemen tetapi tidak sama dengan manajemen. Kepemimpinan merupakan kemampuan yang dimiliki seseorang untuk mempengaruhi orang lain agar bekerja mencapai tujuan dan sasaran. Sedangakan manajemen tidak hanya mencakup kepemimpinan tetapi juga mencakup fungsi-fungsi lainnya seperti perencanaan, 
pengorganisasian, pengawasan dan evaluasi. Kemudian maksud dari kepemimpinan adalah kemampuan seseorang untuk memberikan pengaruh yang menyebabkan seseorang atau kelompok untuk melakukan tugas atau kegiatan secara bersama-sama dalam mencapai tujuan yang diinginkan.

Gaya atau style kepemimpinan Kepala Sekolah mempengaruhi keberhasilan seorang pemimpin dalam mempengaruhi bawahannya. Istilah gaya adalah sama dengan cara yang dipergunakan pemimpin di dalam mempengaruhi para pengikutnya (Mulyasa, 2002). Menurut Mulyasa (2002) gaya kepemimpinan adalah cara yang dipergunakan pemimpin dalam mempengaruhi para pengikutnya. Pendapat lain mengatakan gaya kepemimpinan merupakan norma perilaku yang digunakan oleh seseorang pada saat orang tersebut mencoba mempengaruhi orang lain, seperti yang ia lihat (Mulyasa, 2002). Berdasarkan pengertian tersebut, gaya kepemimpinan adalah cara seorang pemimpin melakukan kegiatan dalam rangka mengarahkan, mempengaruhi, menggerakkan bawahannya dalam mencapai tujuan.

Menurut Sagala (2007) gaya kepemimpinan ada lima macam yaitu a) kepemimpinan otokratis atau diktator atau direktif; b) kepemimpinan demokratis; c) kepemimpinan partisipasif; d) kepemimpinan berorientasi pada tujuan; dan e) kepemimpinan situasional. Kemudian menurut Permadi (2009) Kepala Sekolah sebagai pemimpin yang dikagumi harus memiliki 10 watak positif, yaitu a) jujur; b) kompeten; c) melihat ke depan; d) selalu memicu inspirasi; e) pandai dan cerdas; f) berwawasan luas; g) objektif dan berlaku adil; g) berani mengambil resiko; h) tidak basa-basi, langsung pada persoalan; h) penuh imajinasi.

Peran kepala sekolah pemimpin sangat berpengaruh dalam peningkatan dan kemajuan pendidikan. Kepala Sekolah adalah pemimpin tertinggi di sekolah walaupun kepemimpinan itu sifatnya situasional, artinya suatu tipe kepemimpinan dapat efektif untuk situasi tertentu dan kurang efektif untuk situasi yang lain. Kepemimpinan kepala sekolah adalah cara atau usaha kepala sekolah dalam mempengaruhi, mendorong, membimbing, mengarahkan dan menggerakan guru, siswa, orang tua siswa dan pihak lain yang terkait untuk bekerja/berperan serta guna mecapai tujuan yang ditetapkan. Jabatan Kepala Sekolah pada hakikatnya merupakan amanat dari sang Pencipta (Allah SWT), dan lahirnya amanat dari bangsa dan negara yang secara yuridis formal diangkat berdasarkan surat keputusan (SK) dari pemerintah. Oleh karena itu suatu saat amanat itu akan diminta pertanggungjawabannya baik oleh Allah SWT, maupun oleh bangsa dan negara.

Keinginan menjadi Kepala Sekolah merupakan hal yang positif dan hak bagi setiap guru, sebab tidak mustahil dengan keinginan tersebut akan memotivsi diri 
untuk melaksanakan tugas dan kewajiiban dengan sebaik baiknya. Sesungguhnya menduduki jabatan Kepala Sekolah itu kalau kita kaji secara jujur merupakan beban dan perjuangan yang tidak mudah karena dituntut untuk dapat meningkatkan kualitas pendidikan, oleh karena itu sangat proposional apabila momentum promosi jabatan Kepala Sekolah tetap berakar pada kerangka peningkatan kualitas pendidikan. Secara sederhana Kepala Sekolah adalah orang yang diangkat oleh pihak yang berwenang untuk mengelola suatu sekolah. Selain itu untuk menjadi Kepala Sekolah yang efektif ada beberapa indikator di antaranya adalah sebagai berikut (Mulyasa, 2002).

1. Menerapkan pendekatan kepemimpinan partisipatif terutama dalam proses pengambilan keputusan;

2. Memiliki gaya kepemimipinan yang demokrasi, lugas dan terbuka;

3. Menyiapkan waktu untuk berkomunikasi secara terbuka dengan para guru, peserta didik dan warga sekolah lainnya;

4. Menekankan kepada guru dan seluruh warga sekolah untuk memenuhi normanorma pembelajaran dengan disiplin yang tinggi;

5. Memantau kemajuan belajar peserta didik melalui guru;

6. Menyelenggarakan pertemuan secara aktif, berkala dan berkesinambungan dengan komite sekolah, guru, dan warga sekolah lainnya mengenai topik-topik yang memerlukan perhatian;
7. Membimbing dan mengarahkan guru dalam memecahkan bantuan proposional dan professional;

8. Melakukan berbagai kunjungan kelas untuk mengamatin kegiatan pembelajaran secara langsung;

9. Memberikan dukungan kepada guru untuk menegakkan kedisiplinan peserta didik;

10. Memperhatikan kebutuhan peserta didik, guru, staf, orang tua dan masayarakat sekitar sekolah;

11. Menunjukkam sikap dan perilaku teladan yang dapat menjadi panutan atau model bagi guru, peserta didik, dan seluruh warga sekolah;

12. Memiliki komitmen yang jelas terhadap penjaminan mutu lulusan, mengarahkan perubahan dan inovasi dalam organisasi; dan

13. Memiliki visi yang kuat tentang masa depan sekolahnya dan mampu mendorong semua warga sekolah untuk mewujudkannya.

\section{KESIMPULAN}

Kesimpulan dalam penelitian ini adalah 1) dalam rangka membina dan meningkatkan kompetensi guru, Kepala SMP Negeri 2 Rambatan dalam kepemimpinanya memakai gaya yang tegas keras dan disiplin yang tinggi yang berorentasi pada tugas; 2 ) dalam rangka membina dan meningkatkan motivasi guru untuk meningkatkan mutu hasil belajar siswa, Kepala SMP Negeri 
2 Rambatan memakai gaya demokrasi dalam kepemimpinannya yang berorentasi pada tugas dan manusia; 3) dalam rangka mengembangkan kurikulum, Kepala SMP Negeri 2 Rambatan memakai gaya demokrasi dalam kepemimpinanya; 4) dalam rangka mengelola keuangan dan sarana prasarana sekolah, Kepala SMP Negeri 2 Rambatan memakai gaya situasional.

\section{KEPUSTAKAAN ACUAN}

Departemen Pendidikan Nasional. (2001). Tugas dan Fungsi Kepala Sekolah. Jakarta: Depdiknas RI.

Miles, Mathew dan Huberman. (1992). Qualitative Data Analysis. Terjemahan Tjetjep Rohadi. Jakarta: UI Press.

Moleong, Lexy J. (2005). Metodologi Penelitian Kualitatif. Bandung: Remaja Rosdakarya.

Mulyasa. (2002). Manajemen Kepala Sekolah Profesional. Bandung: PT Remaja Rosda Karya.
Permadi, Dadi. (2009). Kepemimpinana Mandiri Kepala Sekolah. Jakarta: PT Sarana Karya Nusa.

Sagala, Syaiful. (2007). Manajemen Strategik dalam Peningkatan Mutu Pendidikan. Bandung: Alfabeta.

Sinn, Ahmad Ibarhim Abu. (2008). Manajemen Syariah Sebuah Kajian Historis dan Kontemporer. Jakarta: Bumi Aksara.

Sugiyono. (2008). Memahami Penelitian Kualitatif. Bandung: Alfabeta.

Sutopo. (2002). Metodologi Penelitian Kualitatif. Surakarta: Sebelas Maret University Press

Usman, Husaini. (2008). Manajemen, Teori, Praktik, dan Riset. Jakarta: PT Rineka Cipta. Wahjosumidjo. (2011). Kepemimpinan Kepala Sekolah. Jakarta: PT Raja Grafindo Persada. 